\author{
Marquette University \\ e-Publications@Marquette
}

$2-2013$

\title{
Protein Control of S-Nitrosothiol Reactivity: Interplay of Antagonistic Resonance Structures
}

Marat R. Talipov

Marquette University, marat.talipov@marquette.edu

Qadir K. Timerghazin

Marquette University, qadir.timerghazin@marquette.edu

Follow this and additional works at: https://epublications.marquette.edu/chem_fac

Part of the Chemistry Commons

\section{Recommended Citation}

Talipov, Marat R. and Timerghazin, Qadir K., "Protein Control of S-Nitrosothiol Reactivity: Interplay of Antagonistic Resonance Structures" (2013). Chemistry Faculty Research and Publications. 253.

https://epublications.marquette.edu/chem_fac/253 
Marquette University

e-Publications@Marquette

\title{
Chemistry Faculty Research and Publications/College of Arts and Sciences
}

This paper is NOT THE PUBLISHED VERSION; but the author's final, peer-reviewed manuscript. The published version may be accessed by following the link in the citation below.

Journal of Physical Chemistry : B, Vol. 117, No. 6 (February 14, 2013): 1827-1837. DOI. This article is (C) American Chemical Society Publications and permission has been granted for this version to appear in e-Publications@Marquette. American Chemical Society Publications does not grant permission for this article to be further copied/distributed or hosted elsewhere without the express permission from American Chemical Society Publications.

\section{Protein Control of S-Nitrosothiol Reactivity: Interplay of Antagonistic Resonance Structures}

\author{
Marat R. Talipov
}

Department of Chemistry, Marquette University, Milwaukee, Wisconsin Qadir K. Timerghazin*

Department of Chemistry, Marquette University, Milwaukee, Wisconsin 


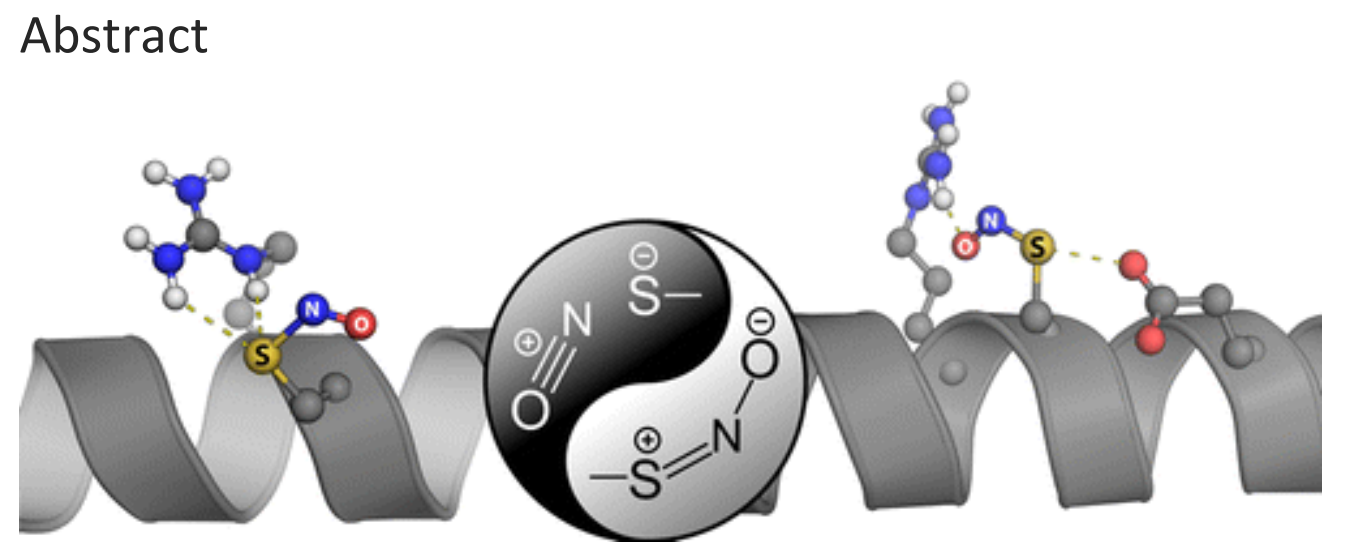

There is currently great interest in S-nitrosothiols (RSNOs) because formation of protein-based RSNOsprotein S-nitrosation-has been recently recognized as a major pathway of the biological function of nitric oxide, NO. Despite the growing number of $S$-nitrosated proteins identified in vivo, enzymatic processes that control reactions of biological RSNOs are still not well understood. In this article, we use a range of models to computationally demonstrate that specific interactions of RSNOs with charged and polar residues in proteins can result in dramatic modification of RSNO structure, stability, and reactivity. This unprecedented sensitivity of the -SNO group toward interactions with charged species is related to their unusual electronic structure that can be elegantly expressed in terms of antagonistic resonance structures. We propose a 'ligand effect map' (LEM) approach as an efficient way to estimate the environment effects on the -SNO groups in proteins without performing electronic structure calculations. Furthermore, the calculated ${ }^{15} \mathrm{~N} N \mathrm{NR}$ signatures of these specific interactions suggest that ${ }^{15} \mathrm{~N}$ NMR spectroscopy can be an effective technique to identify and study these interactions experimentally. Overall, the results of this study suggest that RSNO reactions in vivo should be tightly controlled by the protein environment via modulation of the RSNO electronic structure.

\section{Introduction}

S-Nitrosothiols (RSNOs) have attracted significant attention in chemistry and life sciences due to their role in storage, transport, and biological function of nitric oxide NO in living organisms.(1-4) Biological RSNOs are usually $S$-nitrosated cysteine residues (CysNO) in small peptides or proteins, although the smallest, hydrogensubstituted S-nitrosothiol HSNO has recently been proposed as an important player in NO-related biochemical processes.(5) Reversible $S$-nitrosation of protein cysteine residues(6) has emerged as an important posttranslational modification across a wide variety of living organisms, from bacteria to mammals, $(3,7-15)$ that has been implicated in regulating enzymatic activity, subcellular localization, protein-protein interactions, and protein stability. $(16,17)$ More than 1000 proteins have been already identified to undergo $S$-nitrosation in vivo, $(18,19)$ likely via reactions with nitrogen oxides $\mathrm{NO}_{x}$, dinitrosyl iron complexes, or other $S$-nitrosated proteins or small-molecular weight RSNOs. $(5,11,16,20,21)$ However, despite considerable research effort, there are significant gaps in understanding the biological chemistry of RSNOs and the mechanisms of protein control of their stability and reactivity.

For instance, RSNOs demonstrate dual reactivity in biologically important reactions with thiols that involve a nucleophilic attack by thiol at either the $\mathrm{N}$ or the $\mathrm{S}$ atom of the -SNO group. The $\mathrm{N}$-directed reaction leads to $\mathrm{NO}^{+}$exchange-trans-S-nitrosation,(1) while the $S$-directed reaction-S-thiolation-yields a disulfide and HNO.(22-24) The former reaction is a major pathway of selective protein S-nitrosation in vivo, while the latter may lead to another important post-translational modification of proteins, S-glutathionylation,(25) and production of a powerful biological signaling agent nitroxyl HNO.(26, 27) The mechanisms determining the high selectivity of trans-S-nitrosation(28-35) in vivo are still not clear,(36) and the RSNO S-thiolation in vivo is yet to be conclusively demonstrated. 
In general, the properties of the -SNO group in RSNOs are rather contradictory: although the S-N bond is elongated $\left(\sim 1.8 \AA\right.$ ) and weak (bond dissociation energy, $\left.\mathrm{BDE}_{S-\mathrm{N}} \approx 25-30 \mathrm{kcal} / \mathrm{mol}\right),(37-40)$ the rotation around this bond in not free, as RSNOs have cis and trans conformers separated by a substantial ( $\geq 10 \mathrm{kcal} / \mathrm{mol})$ interconversion barrier, which suggests a partial $\mathrm{S}=\mathrm{N}$ double-bond character. $(38,41,42)$ Moreover, complexation with transition metal ions significantly changes the properties of the -SNO group, e.g., $S$ coordination of $\mathrm{Cu}^{+}$ions greatly destabilizes RSNOs, $(43,44)$ which leads to efficient RSNO decomposition, $(1,43$, 45) whereas $\mathrm{N}$ - and $\mathrm{O}$-coordination of metal ions greatly stabilizes even very unstable RSNOs. $(44,46-48)$ In fact, similar effects can be achieved by coordination of any Lewis acid (LA) to the $\mathrm{S}, \mathrm{N}$, or $\mathrm{O}$ atoms of the -SNO group. $(48,49)$ These puzzling properties of the S-N bonding in RSNOs as well as analysis of the computational data $(39,40)$ point to a complex and an unusual electronic structure of these species.(50)

Recently,(48) we proposed that the complex RSNO electronic structure can be elegantly expressed by representing the $-\mathrm{SNO}$ group in terms of three resonance contributions (Scheme 1). Combination of the conventional resonance structure with a single $\mathrm{S}-\mathrm{N}$ bond, $\mathbf{S}$, and a zwitterionic structure with a double $\mathrm{S}-\mathrm{N}$ bond, $\boldsymbol{D}$, can rationalize RSNO conformations and reactivity trends in substituted RSNOs,(51) and addition of a no-bond ion-pair resonance structure $I$ accounts for the weakness of the S-N bond.(48) Importantly, $\boldsymbol{D}$ and $I$ resonance structures are antagonistic, as they imply opposite bonding patterns and formal charge distributions, and hence impart different stability and chemical reactivity to a RSNO molecule. S-Coordination of a metal cation favors $\boldsymbol{I}$ over $\boldsymbol{D}$ due to electrostatic interactions with opposite formal charges in the two structures, thus destabilizing the $\mathrm{S}-\mathrm{N}$ bond. On the other hand, the formal charge interactions in $\mathrm{O}$ - and $\mathrm{N}$-coordinated complexes favor $\boldsymbol{D}$ over $\boldsymbol{I}$, thus stabilizing the $\mathrm{S}-\mathrm{N}$ bond.(48) The antagonistic resonance structures $\boldsymbol{D}$ and $\boldsymbol{I}$ can coexist because the underlying orbital interactions, $\pi$-conjugation for $D$ and negative hyperconjugation for $I,(48,52)$ are mutually orthogonal as can be demonstrated using natural bond orbital(53) (NBO) analysis (Figure 1). An extension of the NBO method, natural resonance theory(5356) (NRT) supports the resonance description of RSNOs (Scheme 1) and can be used to estimate the resonance weights of the three structures.(48)

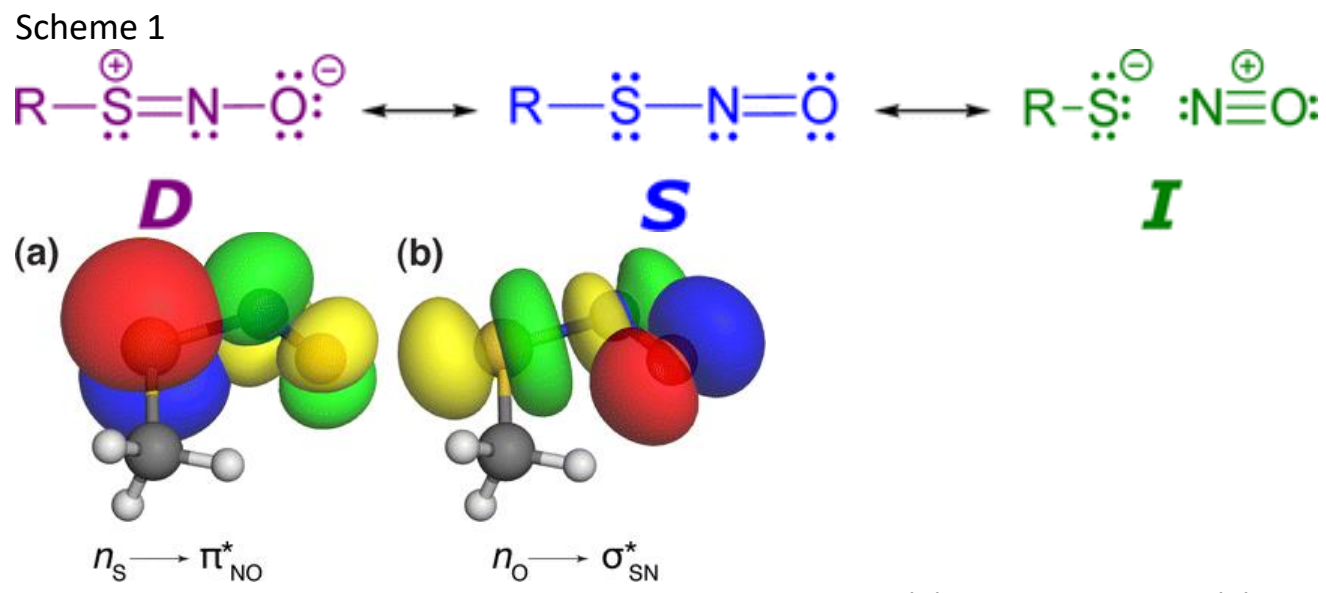

Figure 1. Natural bond orbital interactions in cis-MeSNO: (a) $\pi$-Conjugation, $n(S) \rightarrow \pi^{*}(N-O)$ and (b) negative hyperconjugation, $\mathrm{n}(\mathrm{O}) \rightarrow \sigma^{*}(\mathrm{~S}-\mathrm{N})$.

The antagonistic nature of the -SNO electronic structure also rationalizes the dual reactivity of RSNOs in reactions with nucleophiles: nucleophilic attack at the $\mathrm{N}$ atom is favored by $I$, and nucleophilic attack at the $S$ atom is favored by $\boldsymbol{D}$. In a recent experimental and computational investigation,(49) we demonstrated that a LA coordination can selectively catalyze $\mathrm{N}$ - or $\mathrm{S}$-directed nucleophilic attack by a water molecule by promoting I or $\boldsymbol{D}$, respectively. Therefore, it is possible that proteins can exert tight control over stability and reactivity of bilolgical RSNOs by modulating the -SNO group electronic structure via specific interactions with 
charged residues. $(44,48,49)$ Unfortunately, there is practically no information about specific interactions of -SNO groups in S-nitrosated proteins or protein-RSNO complexes, as very few X-ray structures of S-nitrosated proteins are available(57-61) due to the lability of the S-N bond in RSNOs.

In this article, we report an extensive computational investigation of the effects of charged residues on the properties of the -SNO group using truncated small-molecule and $\alpha$-helix models that reveal a variety of specific interactions that can play an important role in protein control of the reactions of biological RSNOs. Further, we report calculated ${ }^{15} \mathrm{~N}$ NMR signatures of these specific interactions that can be used for their experimental identification. We also propose a parametrized ligand effect map (LEM) technique to quickly estimate the charged residue effects on -SNO groups in the protein environment.

\section{Computational Methods}

Density functional theory (DFT) calculations were performed with the Gaussian 09 package.(62) Although the S$\mathrm{N}$ bond in RSNOs is a problematic case for computational methods, $(39,40)$ the Perdew-Burke-Ernzerhof hybrid functional $(63,64)$ (PBEO) used here is able to reproduce the structure and stability of cis- and trans-HSNO in close agreement with the results of high-level ab initio calculations extrapolated to the CCSDTQ/CBS level(40) (Tables S1 and S2, Supporting Information). Double- and triple- $\zeta$ basis sets def2-SV(P) and def2-TZVPPD by Weigend and Ahlrichs(65) with diffuse functions by Rappoport and Furche(66) were obtained from the EMSL Basis Set Exchange Database. $(67,68)$ The def2-SV (P) basis set was further augmented by a tight $d$ function at the sulfur atom with $\zeta=2.994,(69)$ and the resulting basis set is denoted as def2-SV(P)+d. A detailed discussion of the basis set choice as well as the basis set superposition error (BSSE) effects is provided in the Supporting Information. Solvent effects were included using the implicit integral equation formalism polarizable continuum model(70) (IEF-PCM) with diethyl ether $(\varepsilon=4.24)$ parameters to mimic the protein environment(71) (see Table 1 vs Table S11 and Table S12 vs Table S13, Supporting Information, for comparison of the gas-phase vs solvent results). 
Table 1. Properties of Truncated-Model CysNO Complexes with Charged and Polar Residues Calculated at the PCM-PBE0/def2-TZVPPD Level

\begin{tabular}{|c|c|c|c|c|c|c|c|c|c|}
\hline$x$ & $R_{\mathrm{S}-\mathrm{N},} \AA$ & $R_{\mathrm{N}-\mathrm{O}, \AA}$ & $R_{X-Y}, \AA^{a}$ & $\% D$ & $\% l$ & $\Delta_{\mathrm{As}}{ }^{\mathrm{b}}$ & $\Delta H^{\mathrm{c}}$ & $\mathrm{BDE}_{S \mathrm{~N}}$ & ${ }^{15} N^{d}$ \\
\hline \multicolumn{10}{|l|}{ S-nitrosated cysteine (CysNO) model } \\
\hline cis & 1.757 & 1.185 & & 25 & 9 & & & 32.6 & 0 \\
\hline trans & 1.768 & 1.182 & & 24 & 8 & & & 31.4 & 97 \\
\hline \multicolumn{10}{|l|}{ model of lysine coordinated to the $\mathrm{X}$ atom of CysNO } \\
\hline$S$ & 1.819 & 1.169 & 2.377 & 18 & 12 & -10 & -1.5 & 29.2 & -17 \\
\hline $\mathrm{N}$ & 1.699 & 1.198 & 1.867 & 29 & 6 & 7 & -5.8 & 36.9 & -39 \\
\hline 0 & 1.665 & 1.218 & 1.728 & 36 & 4 & 16 & -6.6 & 39.7 & 29 \\
\hline \multicolumn{10}{|l|}{ model of arginine coordinated to the $\mathrm{X}$ atom of CysNO } \\
\hline $\mathrm{S}$ & 1.808 & 1.171 & 2.589 & 20 & 12 & -8 & -0.6 & 30.1 & -19 \\
\hline $\mathrm{N}$ & 1.713 & 1.195 & 2.023 & 34 & 5 & 13 & -3.4 & 35.4 & -14 \\
\hline 0 & 1.680 & 1.212 & 1.924 & 36 & 5 & 16 & -4.1 & 36.6 & 48 \\
\hline $\mathrm{N}$ and $\mathrm{O}$ & 1.678 & 1.209 & $2.060 / 1.963$ & 34 & 5 & 13 & -6.3 & 38.3 & -13 \\
\hline \multicolumn{10}{|l|}{ model of histidine coordinated by $\mathrm{N} \delta$ to the $\mathrm{X}$ atom of CysNO } \\
\hline $\mathrm{S}$ & 1.805 & 1.173 & 2.469 & 20 & 13 & -9 & -1.0 & 29.8 & -10 \\
\hline $\mathrm{N}$ & 1.708 & 1.196 & 1.900 & 28 & 8 & 4 & -4.6 & 36.4 & -29 \\
\hline 0 & 1.674 & 1.214 & 1.780 & 34 & 5 & 13 & -5.3 & 38.3 & 33 \\
\hline \multicolumn{10}{|l|}{ model of histidine coordinated by $\mathrm{N} \varepsilon$ to the $\mathrm{X}$ atom of Cys NO } \\
\hline $\mathrm{S}$ & 1.810 & 1.171 & 2.418 & 20 & 13 & -9 & -1.0 & 29.6 & -12 \\
\hline $\mathrm{N}$ & 1.703 & 1.703 & 1.905 & 31 & 8 & 4 & -4.8 & 36.6 & -28 \\
\hline 0 & 1.673 & 1.673 & 1.776 & 35 & 7 & 13 & -5.4 & 38.4 & 28 \\
\hline \multicolumn{10}{|l|}{$\begin{array}{l}\text { model of aspartic/glutamic acid (anionic form) coordinated to } \\
\text { the } \mathrm{X} \text { atom of CysNO }\end{array}$} \\
\hline $\mathrm{S}$ & 1.712 & 1.202 & 2.877 & 29 & 6 & 7 & -1.2 & 30.9 & 53 \\
\hline \multicolumn{10}{|l|}{$\begin{array}{l}\text { model of CysNO with S-coordinated Asp/Glu + O-coordinated } \\
\text { Lys cation }\end{array}$} \\
\hline $\mathrm{S}$ and $\mathrm{O}$ & 1.645 & 1.237 & $2.5821 / 1.596$ & 41 & 3 & 23 & & & 29 \\
\hline \multicolumn{10}{|l|}{$\begin{array}{l}\text { model of aspartic/glutamic acid (neutral form) coordinated to } \\
\text { the } X \text { atom of CysNO }\end{array}$} \\
\hline$S$ & 1.786 & 1.178 & 2.435 & 21 & 11 & -5 & -1.2 & 30.5 & 2 \\
\hline $\mathrm{N}$ & 1.715 & 1.195 & 1.898 & 27 & 74 & -2.8 & 34.5 & -12 & \\
\hline 0 & 1.704 & 1.201 & 1.944 & 26 & 6 & 4 & -1.53 & & 50 \\
\hline $\begin{array}{l}\text { model of asparagine/glutamine coordinated to the } \mathrm{X} \text { atom of } \\
\text { CysNO }\end{array}$ & & & & & & & & & \\
\hline
\end{tabular}




\begin{tabular}{|c|c|c|c|c|c|c|c|c|c|}
\hline $\mathrm{S}$ & 1.764 & 1.184 & 2.768 & 24 & 10 & -2 & -0.8 & 31.9 & -5 \\
\hline $\mathrm{N}$ & 1.736 & 1.190 & 2.219 & 27 & 8 & 3 & 0.6 & -33.4 & -46 \\
\hline 0 & 1.731 & 1.193 & 2.137 & 28 & 8 & 4 & -0.5 & 33.6 & 4 \\
\hline
\end{tabular}

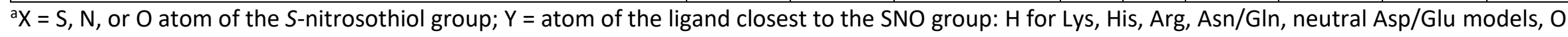
for anionic Asp/Glu.

${ }^{\mathrm{b}} \Delta_{\mathrm{AS}}=(D-I)-(D-I)_{\text {MesNo. }}$

${ }^{\mathrm{c} C o m p l e x a t i o n}$ enthalpy.

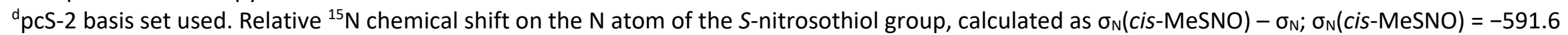
ppm. 
Truncated small-molecule models were optimized with the PBE0/def2-TZVPPD and IEF-PCM solvation model, a combination further referred to as PCM-PBE0/def2-TZVPPD, without any geometric constraints, followed by harmonic frequency calculations. Minimum energy paths were calculated using the nudged elastic band (NEB) technique,(72) as implemented in DL-FIND code(73) interfaced with Gaussian 09 via the ChemShell package.(74) Ligand effect maps (LEMs) were created using a series of semiconstraint optimizations of a ligandMeSNO complex at the PBE0/def2-SV(P)+d level, with the central atom of the ligand fixed with respect to the $S$ atom and the C-S-N plane and the -SNO group geometry relaxed, as shown in Figure 10; a detailed description of the procedure is given in the Supporting Information.

Hybrid quantum mechanics/molecular mechanics calculations of $\alpha$-helix models were performed with the twolayer ONIOM(75) technique with inclusion of solvation effects (ONIOM-PCM/X)(76) using diethyl ether $(\varepsilon=4.24)$ solvent parameters. The high-level layer treated with PBE0/def2-SV(P)+d included the charged residue and Snitrosated cysteine (CysNO) side chain atoms, and the molecular mechanics layer was treated with the Amber94 force field.(77) Force field parameters for the -SNO group were generated with the Antechamber tool(78) using the general AMBER force field (GAFF)(79) and R.E.D.-vIll.4 program(80) to calculate atomic charges. Initial 18residue $\alpha$-helix models composed of alaninie residues with a CysNO residue in the middle and one or two charged residues (Lys, Arg, His, Asp, Glu) at $\pm 1, \pm 3$, and \pm 4 positions relative to CysNO were generated using an in-house Python code based on the Molecular Modeling Toolkit (MMTK) library.(81)

Resonance structure weights were estimated with Natural Resonance Theory (NRT) analysis,(54-56) as implemented in NBO 5.9 code.(82) For consistency, the same set of three reference(54) resonance structures (Scheme 1) was used in all NRT calculations. The gauge-independent atomic orbital (GIAO) method(83) was employed for ${ }^{15} \mathrm{~N}$ NMR shift calculations;(84) isotropic shielding constants were calculated using the PBEO functional and polarization-consistent pcS-2 basis set by Jensen.(85)

\section{Results and Discussion}

\section{Truncated-Model Calculations of S-Nitrosated Cysteine Interactions with Charged and}

\section{Polar Residues}

We first examine the interactions between $S$-nitrosated cysteine, CysNO, with charged and polar protein residues using minimalistic truncated models (Chart 1 ) without any geometric restraints that are likely to play a role in proteins. As it is typical for primary RSNOs, $(41,42)$ the methyl-substituted CysNO model MeSNO (Figure 3 ) is slightly (by $1.2 \mathrm{kcal} / \mathrm{mol}$ ) more stable in the cis form. The geometries and resonance structure weights of the cis and trans conformers are very similar (Table 1). In the following discussion, we focus on the cis conformer, and generally similar results for the trans conformer are compiled in the Supporting Information. Because the effects of RSNO complexation with charged residues would be significantly exaggerated in vacuum, we use a polarizable continuum solvation model for a solvent with $\varepsilon \approx 4$ to mimic the protein environment throughout this study.

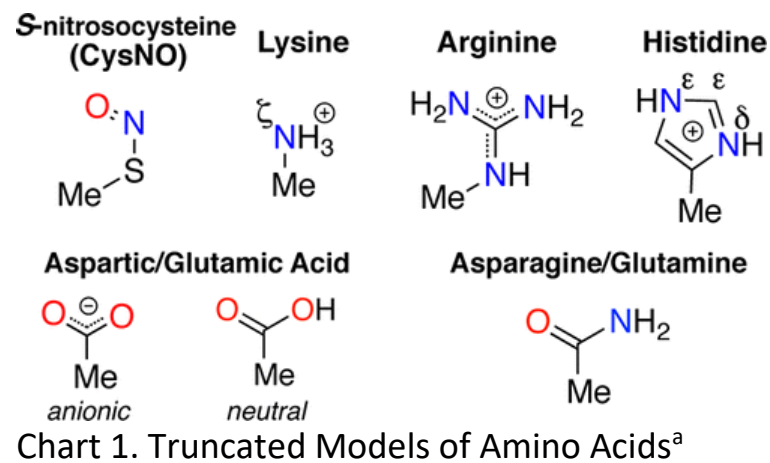


Chart aAtomic labeling with greek letters is used as in original amino acids.

\section{CysNO Interactions with Protonated Basic Residues}

The protonated lysine residue (Lys) model, $\mathrm{MeNH}_{3}{ }^{+}$, can form hydrogen-bonded complexes with all three atoms of the -SNO group (Figure 4). The $\mathrm{O}$ - and $\mathrm{N}$-coordinated complexes are similar in stability (complexation enthalpies of -6.6 and $-5.8 \mathrm{kcal} / \mathrm{mol}$, respectively, Table 1 ), while the $S$-coordinated complex is much weaker $(-1.5 \mathrm{kcal} / \mathrm{mol})$. In agreement with our previous results, $(48,86) O$ - and $N$-coordination modes lead to significant changes of the -SNO group properties: the S-N bond shortens (by 0.1 and $0.05 \AA$, respectively) and becomes stronger (the BDE increases by 7 and $4 \mathrm{kcal} / \mathrm{mol}$ ) as the contribution of $I$ decreases (by $\sim 5 \%$ ) and the contribution of $\boldsymbol{D}$ increases (by $11 \%$ and $4 \%$, Table 1). On the other hand, $S$-coordination has an opposite effect, leading to $\mathrm{S}-\mathrm{N}$ bond elongation (by $0.05 \AA$ ) and weakening (by $3 \mathrm{kcal} / \mathrm{mol}$ ) along with an increase in the contribution of $\boldsymbol{I}$ (by $3 \%$ ) and decrease in $\boldsymbol{D}$ (by $7 \%$ ). These two opposite effects can be related to the increased role of either $\boldsymbol{D}$ or $\boldsymbol{I}$ antagonistic resonance structures in the overall -SNO electronic structure and thus will be referred to as $\boldsymbol{D}$ and $\boldsymbol{I}$ effects (Figure 2). The antagonistic nature of the $\boldsymbol{D}$ and $\boldsymbol{I}$ resonance structures means that an increasing contribution from one structure always coincides with a decrease in the contribution from the other, which leads to significant modification of the -SNO group geometry, stability, and reactivity.

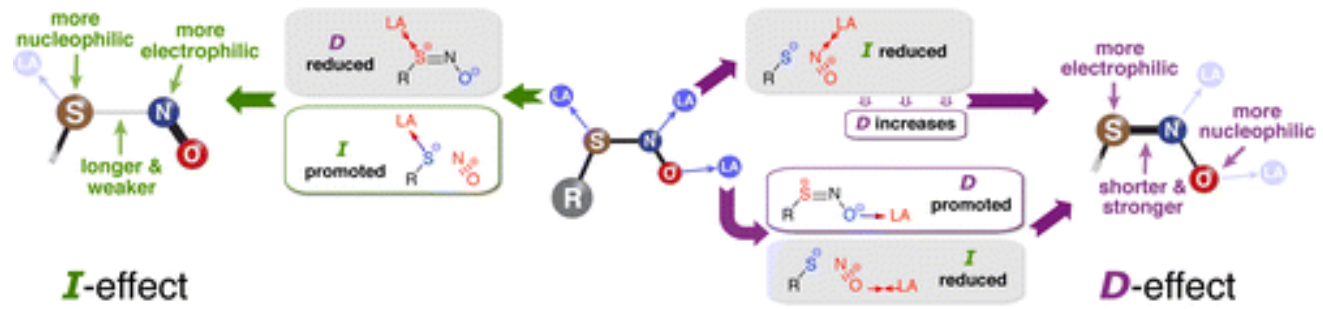

Figure 2. Resonance description of Lewis acid (LA) effects on the electronic structure of RSNO. Electrostatic interactions of a cation or electron-poor neutral LA with the formal charges in $\boldsymbol{D}$ and $\boldsymbol{I}$ antagonistic resonance structures change the relative contributions of $\boldsymbol{D}$ and $\boldsymbol{l}$ into the overall RSNO electronic structure, leading to significant modulation of the -SNO group geometry, stability, and reactivity, which can be summarized as $\boldsymbol{D}$ and $\boldsymbol{I}$ effects.

(a)

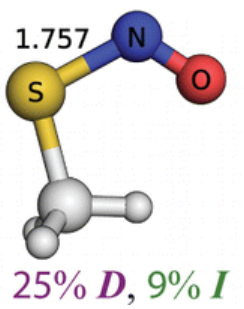

(b)

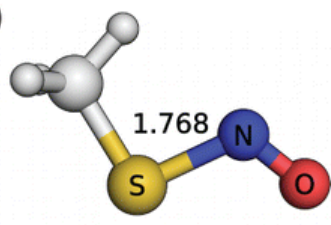

$24 \% D, 8 \% I$

Figure 3. Structures of (a) cis- and (b) trans-MeSNO.

Although the resonance weights of the two antagonistic structures provide a clear description of charged ligand coordination effects on the -SNO group properties, a single numeric parameter representing the relative balance between $\boldsymbol{D}$ and $I$ would be more convenient. Here, we introduce the $\Delta_{\mathrm{AS}}$ parameter calculated as a difference in the resonance weights of the two antagonistic structures (AS) for a given complex relative to the unperturbed MeSNO molecule $\Delta_{\mathrm{AS}}=(D \%-I \%)-(D \%-I \%)_{M e S N O}$ Positive values of $\Delta_{\mathrm{AS}}$ correspond to $D$ effect and negative to $I$ effect. Thus, $\Delta_{A S}=+16$ indicates a strong $D$ effect in the $O$-coordinated Lys model complex, while the $N$-coordinated complex with $\Delta_{\mathrm{AS}}=+7$ has a similar but weaker, $\boldsymbol{D}$ effect. The $\boldsymbol{I}$ effect in the $S$ coordinated complex is characterized by $\Delta_{\mathrm{AS}}=-10$ (Figure 4). 
(a)



(b)

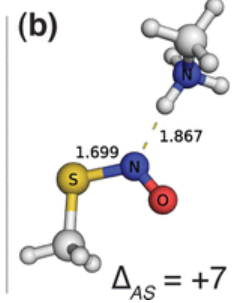



Figure 4. Geometries of complexes of truncated Lys and CysNO models, coordinated at the S, N, or O atom.

We further investigated interconversions between $\mathrm{S}_{-}, \mathrm{N}-$, and $\mathrm{O}$-coordinated Lys-CysNO model complexes by computing the minimum energy path (MEP) using the nudged elastic band (NEB) technique(72) (Figure 5). Evolution of the resonance weights and especially the $\Delta_{\mathrm{AS}}$ parameter (Figure $5 \mathrm{~b}$ and $5 \mathrm{c}$ ) along the MEP highlights a gradual switch from $I$ effect to moderate and then strong $D$ effect as the ligand migrates from the $S$ to the $O$ atom of the -SNO group. The calculated energetic barrier for the transformation from $\mathrm{S}$ - to $\mathrm{N}$-coordinated complex estimated from MEP is $\sim 0.8 \mathrm{kcal} / \mathrm{mol}$ (Figure 5a), and the enthalpic barrier obtained from subsequent transition structure calculation is even smaller, $\Delta H^{\ddagger} \approx 0.3 \mathrm{kcal} / \mathrm{mol}$. The barrier between $N$ - and $O$-coordinated complexes estimated from MEP is slightly higher, $\sim 2.0 \mathrm{kcal} / \mathrm{mol}$.(87) These small barriers cannot prevent rapid interconversion between the $S-, N-$, and $\mathrm{O}$-coordinated complexes that would result in formation of the most energetically stable $\mathrm{O}$-coordinated complex if there are no geometric restrictions on the interacting groups. However, it is possible that less favorable $\mathrm{N}$ - and even $\mathrm{S}$-coordinated complexes could be stabilized in protein environment due to spatial restraints.
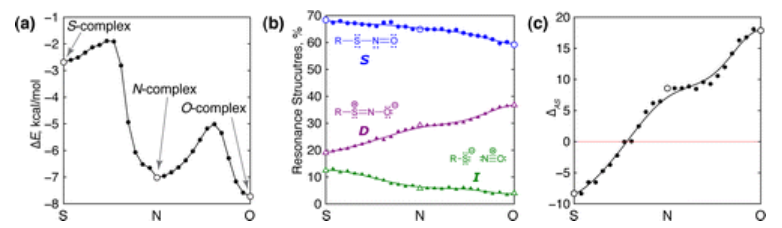

Figure 5. Minimum energy path connecting the $\mathrm{S}$ to $\mathrm{N}$ to $\mathrm{O}$ complex of cis-MeSNO and $\mathrm{MeNH}_{3}{ }^{+}$: (a) Interaction energy relative to separated ligands; (b) resonance structure weights calculated using NRT; (c) $\Delta_{\mathrm{AS}}$ index indicating a switch from $\boldsymbol{D}$ effect to $\boldsymbol{I}$ effect along the path from the $\mathrm{S}$ - to the $\mathrm{N}$-coordinated complex.

The complexation effects of a protonated arginine residue (Arg) on the -SNO group are very similar to the lysine model despite slightly lower (by $\sim 2 \mathrm{kcal} / \mathrm{mol}$ ) binding energies (Table 1, Figure S2, Supporting Information). In these complexes, Arg is predominantly coordinated to the -SNO group by one of the two charge-bearing $=\mathrm{NH}_{2}$ groups, but a complex with simultaneous $\mathrm{O}$ - and $\mathrm{N}$-coordination is also possible; although this complex is $\sim 2 \mathrm{kcal} / \mathrm{mol}$ stronger than the $O$-coordinated complex, the magnitude of the $\boldsymbol{D}$ effect is very similar in both cases (Table 1). A protonated histidine (His) residue model can coordinate to the $-\mathrm{SNO}$ group with either $\mathrm{N}^{\delta}-\mathrm{H}$ or $\mathrm{N}^{\varepsilon}-\mathrm{H}$ groups (Figure S3, Supporting Information); both modes of coordination have very similar effects and follow the same trends as Lys and Arg complexes (Table 1). Importantly, interactions with CysNO can also affect the properties of His residues, such as $\mathrm{p} K_{\mathrm{a}}$, and the ability of His residues to deprotonate or protonate at nearly neutral $\mathrm{pH}$ may play an important role in the catalysis of CysNO reactions in proteins.

\section{CysNO Interactions with Deprotonated Acidic Residues and Dual-Coordination Effects}

Negatively charged species (or Lewis bases in general) can be predicted to modulate RSNO electronic structure in a similar way to Lewis acids (Figure 2) but with inverse effects (Figure 7). Although no stable complexes could be located with a deprotonated acidic residue model MeCOO- (Chart 1 ) coordinated at either $\mathrm{O}$ or $\mathrm{N}$ atoms of the -SNO group, we located a weak (binding enthalpy $-1 \mathrm{kcal} / \mathrm{mol}$ ) complex with a $S$-coordinated carboxylic oxygen in the SNO plane (Figure 6a). This complex is likely stabilized by $\sigma$-hole interaction similar to well-studied 
halogen bonding.(88) In this complex, formal charge interactions disfavor I with a negatively charged $\mathrm{S}$ atom and favor $\boldsymbol{D}$ that has a positively charged $\mathrm{S}$ atom (Figure 7), leading to a moderate $\boldsymbol{D}$ effect with $\Delta_{\mathrm{AS}}=+7$ (Table 1). However, a very strong $\boldsymbol{D}$ effect can be achieved by simultaneous $S$-coordination of a negatively charged acidic residue and $O$-coordination of a positively charged basic residue (Figure $6 \mathrm{~b}$ ). In this case, the effects of the basic and acidic residues on the -SNO group are essentially additive, as the overall $\Delta_{A S}=+23$ is the same as the sum of the basic $\Delta_{\mathrm{AS}}=+16$ and acidic $\Delta_{\mathrm{AS}}=+7$ residue models. Interestingly, Abrams and co-workers recently postulated that formation of a similar Glu-CysNO-Arg bridge can be involved in conformational changes in apolipoprotein E3 that play a role in the development of Alzheimer's disease.(89) However, our computational results highlight that besides the proposed structural importance of these interactions they also dramatically modify the -SNO group stability and reactivity, as the strong $\boldsymbol{D}$ effect may prevent denitrosation of CysNO in this and similar structural motifs in proteins.

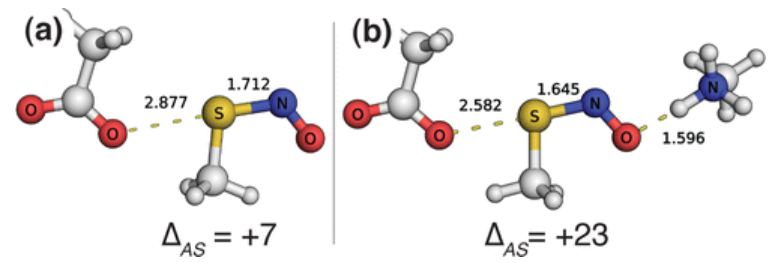

Figure 6. Geometries of a complex between Asp/Glu and CysNO models (a) and a CysNO model dual coordinated by negatively and positively charged residue models (b).



Figure 7. Resonance description of the negatively charged species effect on RSNO electronic structure.

\section{CysNO Interactions with Noncharged Residues}

Interactions with noncharged polar protein residues can also modulate the -SNO group electronic structure and properties. For instance, the neutral acidic residue model $\mathrm{MeCOOH}$ can act as a Lewis acid in hydrogen-bonded complexes with the CysNO model (Figure S8, Supporting Information). The binding energies of the $S$ - and $O$ coordinated complexes are similar to the $S$-coordinated complex of the anionic form ( $<1.5 \mathrm{kcal} / \mathrm{mol}$, Table 1$)$, although the $N$-coordinated complex is stronger $(\sim 3 \mathrm{kcal} / \mathrm{mol})$. The coordination effects are similar to charged Lewis acid complexes but weaker: $\Delta_{\mathrm{AS}}=+4$ for $\mathrm{N}$ - and $\mathrm{O}$-coordination, and $\mathrm{S}$-coordination results in $\Delta_{\mathrm{AS}}=-5$. We also found that asparagine Asn and glutamine $\mathrm{Gln}$ model $\mathrm{MeC}(=0) \mathrm{NH}_{2}$ can form weak ( $<1 \mathrm{kcal} / \mathrm{mol}$ ) complexes with the $-\mathrm{SNO}$ group via its $-\mathrm{NH}_{2}$ group. These complexes exhibit the same properties as positively charged models, although the effect is weaker: complexation energy does not exceed $0.8 \mathrm{kcal} / \mathrm{mol}$, and $\Delta_{\mathrm{As}}$ is equal to $-2,+3$, and +4 for $S-, N-$, and $O$-coordination, respectively.

To conclude, three RSNO complexation modes with Lewis acids, such as protonated basic residues, neutral acidic residues, and polar residues, and one coordination mode with negatively charged bases, such as ionized acidic residues, provide a convenient way to control RSNO stability and reactivity in the protein environment. Complexation can significantly modify the electronic structure of the -SNO group, resulting in either $\boldsymbol{D}$ or $\boldsymbol{I}$ effects (Figures 2 and 7 ) that promote the corresponding antagonistic resonance structure and reduce the other. These effects can be represented by the $\Delta_{\mathrm{AS}}$ parameter that reflects an increase in either zwitterionic character of the -SNO group, represented by structure $\boldsymbol{D}$, or ionic character, represented by structure $I$. Good correlations of $\Delta_{\mathrm{AS}}$ with both $R_{\mathrm{S}-\mathrm{N}}$ and $\mathrm{BDE}_{\mathrm{S}-\mathrm{N}}$ (Figure 8) highlight the interrelation between the RSNO electronic structure and its geometry and reactivity. Figure 8 also visually represents the variation of the 
-SNO group properties in the presence of charged residues: the calculated S-N bond lengths span the 1.65-1.81 $\AA$ A range, and the $\mathrm{S}-\mathrm{N}$ bond homolytic dissociation energy can vary by more than $10 \mathrm{kcal} / \mathrm{mol}$. By extension, other important parameters thermodynamically related to $\mathrm{BDE}_{\mathrm{s}-\mathrm{N}}$, e.g., RSNO redox potential,(4) may significantly vary depending on the specific interactions of the -SNO group.
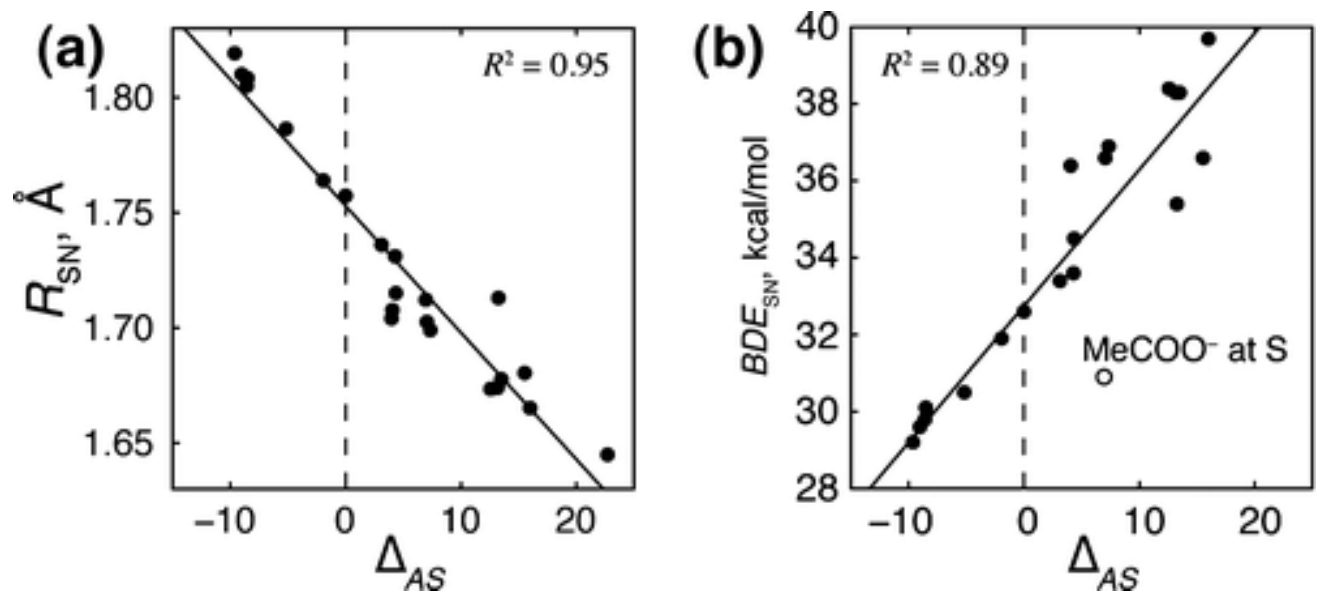

Figure 8. Correlation between $\Delta_{\mathrm{AS}}$ and (a) $\mathrm{S}-\mathrm{N}$ interatomic distance and (b) $\mathrm{S}-\mathrm{N}$ bond dissociation energy (complex with Asp/Glu model is excluded from the correlation).

\section{CysNO Interactions with Charged Residues in an $\alpha$-Helix Model}

Although truncated small-molecule models are useful to establish the effect of charged residue coordination on the CysNO properties, they may not be representative of the -SNO group interactions in proteins, where residue positions are constrained by the protein scaffold. Unfortunately, the available experimental structural data on $S$ nitrosated proteins is too scarce to allow a systematic investigation of possible specific interactions involving CysNO residues. Thus, to gain basic understanding of the role of spatial constraints in the protein environment, we performed a systematic modeling of all possible specific interactions between a CysNO residue with charged residues embedded in a short, 18-residue $\alpha$-helix model with a hybrid quantum mechanics/molecular mechanics ( $Q M / M M)$ approach. We combinatorially generated a set of initial structures for 30 models with a single charged residue (Lys, Arg, His, Asp, Glu) and 108 models with one acidic and one basic residue at proximal positions ( \pm 1 , $\pm 3, \pm 4)$ relative to CysNO and optimized their geometries with $\mathrm{QM} / \mathrm{MM}$. These calculations yielded 23 structures with a single charged residue interacting with the -SNO group and 46 structures with CysNO dual coordinated by a basic and acidic residue.

Due to technical difficulties with the NRT analysis of QM/MM results, the $\mathrm{S}-\mathrm{N}$ bond length $R_{\mathrm{S}-\mathrm{N}}$ was used to characterize the change in the electronic structure of the -SNO group, an approach justified by the truncatedmodel results that show good correlations between $R_{S-N}$ and the weights of $\boldsymbol{D}$ and $\boldsymbol{I}$ resonance structures (Figure S9, Supporting Information) as well as with the $\Delta_{\mathrm{AS}}$ parameter (Figure 8). Thus, the $R_{\mathrm{S}-\mathrm{N}}$ change relative to unperturbed CysNO, $\Delta R_{\mathrm{S}-\mathrm{N}}$, can be used as a metric of the $D$ effect $\left(\Delta R_{\mathrm{S}-\mathrm{N}}<0\right)$ or $I$ effect $\left(\Delta R_{\mathrm{S}-\mathrm{N}}>0\right)$.

Most of the calculated $\alpha$-helical complexes of CysNO with a single basic residue demonstrate a moderate to strong $\boldsymbol{D}$ effect with $-\Delta R_{\mathrm{S}-\mathrm{N}} \leq 0.1 \AA$ (Table S14, Supporting Information). The magnitude of the $\boldsymbol{D}$ effect for complexes without significant steric hindrance is comparable to the truncated-residue model complexes (Figure 9a and 9b), although steric factors significantly affect the complex geometry for a majority of the complexes, thus decreasing the effect of complexation on the -SNO group. Surprisingly, dual coordination of a positively charged basic and a negatively charged acidic residue to CysNO within the $\alpha$-helical scaffold can have a stronger effect on the -SNO group compared to the truncated-residues model. For example, for a CysNO complex with Lys and Asp at -1 and +4 positions in an $\alpha$-helix (Figure 9c) the complexation effect $\Delta R_{S-N}=-0.17 \AA$ 
is significantly stronger compared to the corresponding truncated-residue model for which $\Delta R_{\mathrm{S}-\mathrm{N}}=-0.13 \AA$, both calculated at the PCM-PBE0/def2-SV(P)+d level; calculations with the larger def2-TZVPPD basis set show a similar effect with $\Delta R_{S-N}$ values of -0.14 and $-0.11 \AA$, respectively. In this $\alpha$-helical complex (Figure 9c) the charged groups are located out of the -SNO plane, a nonoptimal orientation for the complex formed by free small-molecule models (Figure $6 \mathrm{~b}$ ). Thus, steric constraints within the protein environment may amplify the charged residue effect on the -SNO group.


Figure 9. Complexes of the $S$-nitrosothiol group incorporated in the $\alpha$-helix: (a) with Lys at position +3 , (b) with Glu at position -1 , and (c) dual-coordinated complex, which shows the strongest effect on the $\mathrm{S}-\mathrm{N}$ bond. In uncoordinated CysNO in the $\alpha$-helix, $R_{S-N}=1.769 \AA$.

The CysNO S-N bond in $\alpha$-helical complexes can also be elongated by $S$-coordination of a basic residue, leading to the $I$ effect on the -SNO group, although we were able to locate only six of these complexes (Table S14, Supporting Information, rightmost column).

\section{Ligand Effect Maps (LEMs) for the -SNO Group Interactions with Charged Residues}

Calculations of truncated small-molecule and artificial $\alpha$-helix models revealed a variety of mechanisms that can modulate -SNO reactivity in proteins. However, finding specific interactions involving -SNO groups in actual proteins and determining their significance is a much more difficult task, even with good experimental structures of S-nitrosoproteins at hand. Spatial constraints may prevent charged residues and -SNO groups from achieving the same orientations as in the corresponding model complexes, which may decrease or increase the complexation effect on the -SNO electronic structure, as observed in CysNO complexes in model $\alpha$-helices (Figure 9c). Detailed QM/MM calculations can be used to determine the extent of charged residue influence on a CysNO residue in a given protein, but they are too computationally expensive to search for functionally important -SNO group interactions across a large number of $S$-nitrosated proteins. Therefore, an efficient methodology that allows quick assessment of charged residue effects on CysNO without preforming electronic structure or QM/MM calculations can be very useful for preliminary identification of these interactions.

Analysis of the truncated-model results (Table 1 ) suggests that the $\boldsymbol{D}$ and $\boldsymbol{I}$ effects of the three protonated basic residues are identical quantitatively and very similar qualitatively and that the effects of charged basic and acidic residues are approximately additive. Thus, it should be possible to estimate charged ligand effects on -SNO groups in protein environment using the results obtained from corresponding truncated models. Here, we propose to use truncated-model data calculated for a wide range of relative positions of a ligand and -SNO group to construct three-dimensional ligand effect maps (LEMs) that can be used for quick estimation of 
expected charged-residue effect on the -SNO group. LEMs are constructed using a probe molecule as a model of a charged residue, e.g., $\mathrm{NH}_{4}{ }^{+}$, that is placed at different positions around the $\mathrm{C}-\mathrm{S}-\mathrm{N}$ atoms on a grid (Figure 10a). For each grid point, a constrained optimization is performed with the probe fixed at its central atom and its effect on the -SNO group properties is evaluated (Figure 10b). The ligand effects on the -SNO group for different ligand positions are assembled into LEMs for each property of interest, which can be visualized using isosurface representation (Figure 11). Construction of LEMs for a given ligand requires a large number ( 2000) of constrained optimizations, but once a LEM is constructed, it can be used to estimate complexation effects on a -SNO group from known relative position of the ligand at virtually no computational cost. The procedure used to construct LEMs is described in detail in the Supporting Information.

(a)


Figure 10. Three-dimensional ligand effect maps (LEMs). (a) To construct LEMs, a probe ligand, e.g., $\mathrm{NH}_{4}{ }^{+}$, is fixed by its central atom $L$ relative to the $S$ atom and the $\mathrm{C}-\mathrm{S}-\mathrm{N}$ plane and the $-\mathrm{SNO}$ geometry geometry is relaxed in the presence of the ligand. Ligand effects on the -SNO group for different ligand positions are assembled into 3dimensional grids of data-LEMs - for various properties (b): each sphere corresponds to a position of the probe, and the sphere color shows the degree of the effect, e.g., red for positive and blue for negative $\Delta R_{\text {s- }}$ ${ }_{N}$ values, as shown. The -SNO group geometry is drawn as in unperturbed MeSNO, although it is different for each grid point.



(a) $\mathrm{NH}_{4}^{+}$probe



(b) $\mathrm{MeCOO}^{-}$probe

Figure 11. Isosurface representations of ligand effect maps (LEMs) for the $\Delta_{\text {As }}$ parameter obtained with basic (a) and acidic (b) residue models as probes. If a probe is placed within the volume encompassed by an isosurface, the effect on the -SNO group should be equal to or greater than the isosurface cutoff.

We constructed a set of LEMs for several -SNO group properties using the MeSNO model and $\mathrm{NH}_{4}{ }^{+}$and MeCOO- probe ligands. Expectedly, isosurface representation of $\triangle_{\mathrm{AS}} \mathrm{LEM}$ obtained with the positively charged probe has two distinct areas (Figures 11a): one corresponding to the $\boldsymbol{D}$ effect around the $\mathrm{O}$ and $\mathrm{N}$ atoms of the -SNO group and one corresponding to $I$ effect around the $S$ atom. The situation is inverse in the case of the negatively charged probe (Figures $11 \mathrm{~b}$ ). To validate the LEM approach as a predictive tool, we compared the complexation effects of charged residues obtained from truncated-model and model $\alpha$-helix results vs estimations obtained from LEMs. LEM predictions were generated by measuring the position of the ligand's charge-bearing $\mathrm{N}$ or $\mathrm{O}$ atom relative to the $\mathrm{C}-\mathrm{S}-\mathrm{N}$ group $(R, \alpha$, and $\theta$, Figure $10 \mathrm{a})$ in a complex and taking the LEM value that corresponds to the same relative coordinates. Good correlations were found between the $R_{S-}$ ${ }_{N}$ and the $\Delta_{\text {AS }}$ parameters predicted from LEMs and obtained from the electronic structure calculations (Figure 12a and 12b) for both small-molecule complexes and $\alpha$-helix models. High quality of these correlations $\left(R^{2} \approx 0.95\right)$, with slopes very close to unity and near-zero intercepts, is especially remarkable considering that in 
the case of protonated basic residues the results for Lys, Arg, and His complexes were estimated from LEMs obtained with $\mathrm{NH}_{4}^{+}$probe.
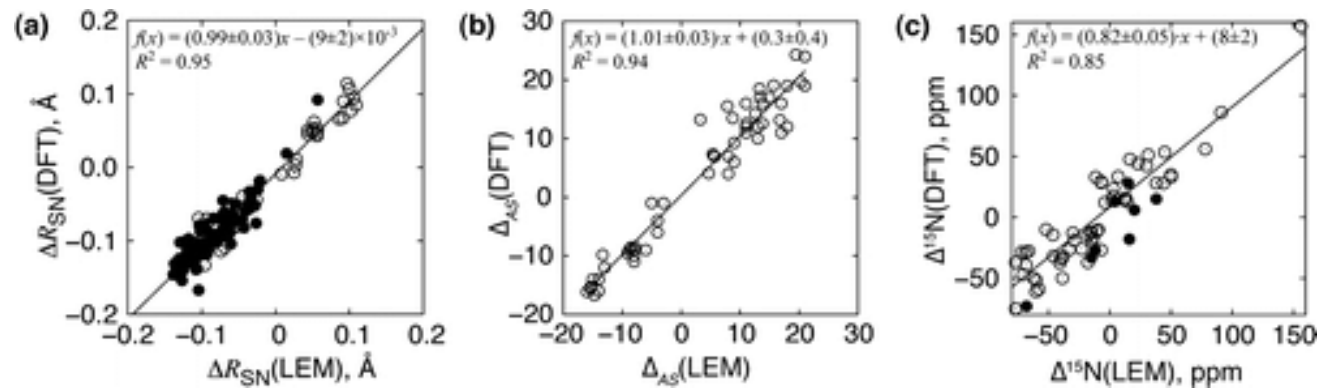

Figure 12. Comparison of LEM predictions with PBE0/def2-TZVPPD results: (a) $R_{S-N}, \AA$, (b) $\Delta_{A S}$, and (c) NMR ${ }^{15} \mathrm{~N}$, ppm (truncated model results, dotted circles; $\alpha$-helix models, black circles (excluded from correlation analyses)).

LEMs obtained in here can be used to estimate the environment effects on the -SNO groups from the relative positions of charged residues in modeled or experimental X-ray structures of S-nitrosated proteins. These specific environment effects cannot be reproduced with standard force-field models and may be too subtle to discern from standard resolution X-ray structures but still can play an important role in regulating -SNO stability and reactivity. Using LEMs, these possible interactions can be pinpointed and chosen for more detailed analysis. Figure 13 shows an example application of the LEM approach to $S$-nitrosated human thioredoxin-1 X-ray structure(59) (PDB 2HXK, chain B), where the -SNO group of S-nitrosated Cys69 is within $\sim 3 \AA$ of the Lys85 $\mathrm{N}^{3}$ atom. This charge-bearing atom is inside the volume encompassed by a LEM isosurface corresponding to $R_{\mathrm{s}}$ $\mathrm{N} \geq 0.03 \AA$, which suggests that the CysN069-Lys85 interaction may warrant further experimental or computational investigation. Although it is not clear at the moment if this interaction persists in the solution structure of $S$-nitrosated thioredoxin and thus has biochemical relevance,(90) this example demonstrates the utility of LEMs for structural analysis of S-nitrosated proteins.

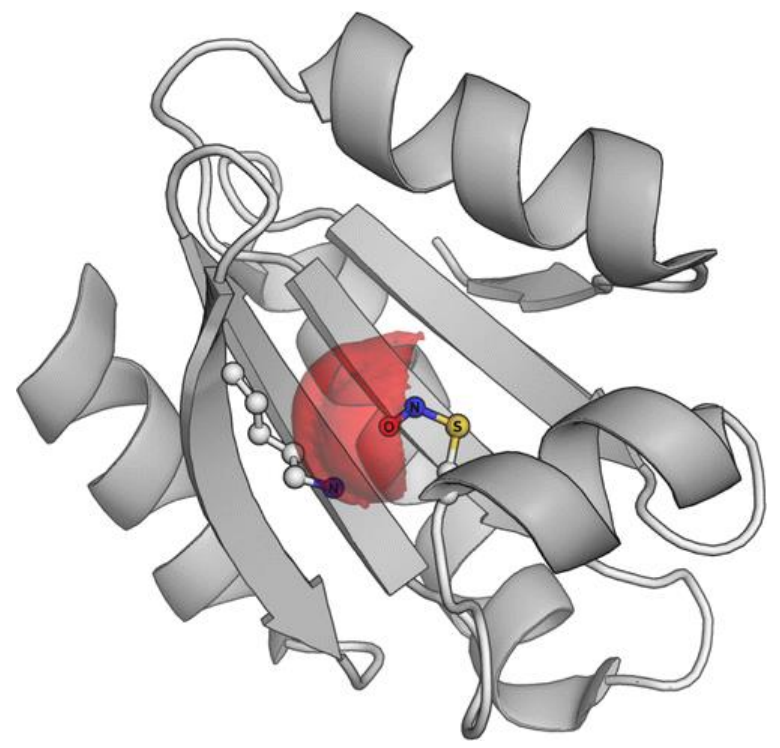

Figure 13. X-ray structure of human thioredoxin S-nitrosated at Cys69 (PDB 2HXK, chain B) with the MeSNO$\mathrm{NH}_{4}{ }^{+}$LEM describing the basic residue effect on $\Delta D \%$ applied on the $-\mathrm{SNO}$ group. Charge-bearing $\mathrm{N}$ atom of Lys 85 is within the LEM isovalue corresponding to a $\geq 4 \%$ increase in $D$.

Another utility of the LEM approach is that it provides a clear conceptual picture of the charged species effect on the $-\mathrm{SNO}$ group. A positively charged group located in the proximity of the $\mathrm{N}-\mathrm{O}$ group causes the $\boldsymbol{D}$ effect, 
irrespective to specific orientation or coordination (Figure 11a), which is in very good agreement with the considerations based on the formal charges in the two antagonistic structures (Figure 2). Similarly, a positively charged ligand near the $S$ atom causes the $I$ effect, irrespective to its relative orientation. Quantitatively, there is a very robust correlation between the antagonistic resonance structure parameter $\Delta_{\mathrm{AS}}$ and $\Delta R_{\mathrm{S}-\mathrm{N}}$ for all points from the MeSNO- $\mathrm{NH}_{4}{ }^{+}$LEM (Figure 14a). On the other hand, $\Delta R_{\mathrm{s}-\mathrm{N}}$ correlations with the strengths of $\mathrm{n}(\mathrm{S}) \rightarrow$ $\pi^{*}(\mathrm{~N}-\mathrm{O}) \pi$ conjugation and $\mathrm{n}(\mathrm{O}) \rightarrow \sigma^{*}(\mathrm{~S}-\mathrm{N})$ negative hyperconjugation (Figure 1 ), the orbital interactions behind the antagonistic resonance structures $\boldsymbol{D}$ and $\boldsymbol{I}$, are significantly worse (Figure 14b), which suggests a complex interplay between different orbital interactions in the LA-RSNO complexes. At the same time, antagonistic resonance structures (Figure 2) provide a clear qualitative and, with the help of NRT analysis, quantitative picture of the -SNO properties modulation by charged ligands.

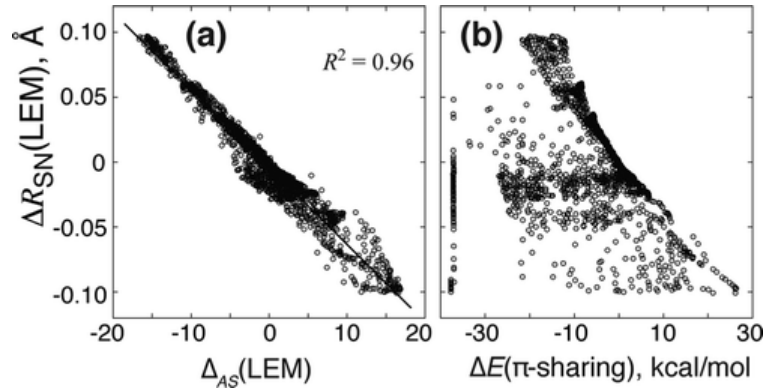

Figure 14. MeSNO- $\mathrm{NH}_{4}{ }^{+} \mathrm{LEM}$ : correlations between the change in $\mathrm{S}-\mathrm{N}$ distance $\Delta R_{\mathrm{S}-\mathrm{N}}$ with (a) $\Delta_{\mathrm{AS}}$ parameter and (b) the change in $\mathrm{n}(\mathrm{S}) \rightarrow \pi^{*}(\mathrm{~N}-\mathrm{O}) \pi$-conjugation energy calculated with the NBO approach.

\section{${ }^{15}$ N NMR Signatures of Specific Interactions of -SNO Groups and Charged Residues}

The computational results presented in this work suggest that specific interactions of -SNO groups with charged and polar residues in S-nitrosated proteins can play an important role in RSNO biochemistry. Because highresolution X-ray crystallography of $\mathrm{S}$-nitrosated proteins is challenging due to the fragility of the $\mathrm{S}-\mathrm{N}$ bond in RSNOs, alternative experimental approaches to identify and study these specific interactions could be very useful. In this respect, ${ }^{15} \mathrm{~N}$ NMR spectroscopy could provide a convenient way of probing the immediate environment of ${ }^{15} \mathrm{~N}$-labeled -SNO groups in proteins in solution.

${ }^{15} \mathrm{~N}$ NMR spectroscopic techniques have been repeatedly used in RSNO chemistry and biochemisty. $(5,7,41,42$, 91-94) The ${ }^{15} \mathrm{~N}$ chemical shift of the -SNO group is relatively insensitive to substitiuents, e.g., it varies within 5 ppm for various primary RSNOs.(93) At the same time, the $-\mathrm{SNO}{ }^{15} \mathrm{~N}$ chemical shift is sensitive to the conformation, with $\sim 60-70$ ppm difference between cis and trans conformers. $(41,42)^{15} \mathrm{~N}$ chemical shift calculations for small-molecule models (Table 1) as well as the corresponding LEMs (Figure 15a) suggest that ${ }^{15} \mathrm{~N}$ NMR can be used in combination with other experimental techniques and computational modeling to identify and study specific interactions in $S$-nitrosated proteins. Basic residue $O$-coordination leads to $\mathrm{N}$ atom shielding, $\Delta \delta=30-40 \mathrm{ppm}$ shift relative to uncoordinated CysNO, while $N$-coordination results in deshielding with $\Delta \delta=$ -15 to $-30 \mathrm{ppm}$ shift (Table 1 ). $\mathrm{S}$-Coordination of positively charged basic residues also leads to $\mathrm{N}$ atom deshielding with $\Delta \delta=-10$ to $-20 \mathrm{ppm}$, but $S$-coordination of negatively charged acidic residues results in significant shielding with $\Delta \delta>50 \mathrm{ppm}$. The ${ }^{15} \mathrm{~N} \Delta \delta$ values estimated for truncated-model complexes using LEMs (Figure 15a) agree well with the calculated values presented in Table 1(Figure 12c). Thus, the LEM approach can be useful to estimate NMR spectroscopic signatures of specific interactions involving -SNO groups in proteins, as shown on the example of S-nitrosated Cys94 interaction with Lys133 in S-nitrosated(95) structure of $\mathrm{Ca}^{2+}$ binding protein calbindin- $\mathrm{D}_{28 \mathrm{~K}}$ modeled with $\mathrm{QM} / \mathrm{MM}$ (Figure 15b) based on the experimental NMR structure of non-nitrosated form.(96) 



Figure 15. MeSNO- $\mathrm{NH}_{4}{ }^{+} \mathrm{LEM}$ for the -SNO group ${ }^{15} \mathrm{~N}$ NMR shift relative to uncoordinated CysNO (a) can be applied to the QM/MM-preoptimized structure of calbindin- $D_{28 k}$ with $S$-nitrosated Cys94 (b, only $\Delta \delta=-45$ isosurface is shown), which suggests that the predicted interaction with Lys133 may be detected experimentally using ${ }^{15} \mathrm{~N}$ NMR. A model constructed on the basis of the non-nitrosated calbindin- $\mathrm{D}_{28 \mathrm{~K}} \mathrm{NMR}$ structure (PDB 2G9B); ONIOM[PBE0/def2-SV(P)+d:Amber] optimization was used to relax the $S$-nitrosated form.

\section{Conclusions and Outlook}

A systematic computational study using truncated-residue model complexes and a short $\alpha$-helix model demonstrated that charged and, to a lesser degree, polar residues can strongly affect the electronic structure of the -SNO group in the protein environment. This modulation of the RSNO electronic structure can be rationalized using the concept of the antagonism between two of the three -SNO group resonance structures: zwitterionic $D, \mathrm{RS}^{+}=\mathrm{N}-\mathrm{O}^{-}$, vs ion-pair $I, \mathrm{RS}^{-} \ldots \mathrm{NO}^{+}$(Scheme 1 ). Charged residue interactions with opposite formal charges implied by the antagonistic structures promote one structure and reduce the contribution of another. This results in significant modification of the -SNO group geometry, stability, and reactivity: either shortening and strengthening of the $\mathrm{S}-\mathrm{N}$ bond and increasing electrophilicity of the $\mathrm{S}$ atom ( $\boldsymbol{D}$ effect) or lengthening and weakening of the $\mathrm{S}-\mathrm{N}$ bond and increasing electrophilicity of the $\mathrm{N}$ atom ( $\boldsymbol{I}$ effect). Computed three-dimensional ligand effect maps (LEMs) show that modulation of the RSNO properties can be achieved by a variety of relative orientations of a charged ligand relative to the -SNO group. The LEMs obtained in this work can be used to estimate the effects of possible specific interactions that may affect CysNO residues using experimental or computed protein structures. These interactions can be studied experimentally using ${ }^{15} \mathrm{~N}$ NMR spectroscopy, as our calculations show that the chemical shift of the -SNO group $\mathrm{N}$ atom is sensitive to complexation with charged residues.

Ubiquity of RSNOs in biological systems and the effectiveness of the mechanisms available to control the RSNO reactivity in protein environment suggests that these mechanisms may be involved in a variety of important biochemical processes. This control may be responsible for selectivity of trans-S-nitrosation reactions, stabilization or destabilization of certain CysNOs in proteins, catalysis of otherwise unlikely $S$-thiolation reactions, etc. Importantly, relatively small rearrangements may be sufficient to switch the reactivity of the -SNO group, which opens ample opportunities for efficient allosteric control of RSNO reactions. Further progress in understanding the enzymatic control of RSNO reactivity will depend on combined experimental and computational identification of specific examples of mechanistically significant specific interactions of -SNO groups in S-nitrosated proteins. Besides efficient experimental techniques to study these interactions, such

as ${ }^{15} \mathrm{~N}$ NMR spectroscopy proposed here, extensive molecular dynamics simulations with reliable force-field description of the -SNO group will be of great importance in this effort. Optimization of such -SNO force field based on the extensive computational data obtained in this work is underway.

\section{Supporting Information}

Additional computational details: discussion of the basis set choice, natural resonance theory calculations, $\mathrm{QM} / \mathrm{MM}$ calculations, construction of ligand effect maps; gas-phase calculation results and data for trans- 
MeSNO complexes; supplementary Tables S1-S14 and Figures S1-S12; Cartesian coordinates and energies for all calculated structures.

This material is available free of charge via the Internet at http://pubs.acs.org.

The authors declare no competing financial interest.

\section{Terms \& Conditions}

Electronic Supporting Information files are available without a subscription to ACS Web Editions. The American Chemical Society holds a copyright ownership interest in any copyrightable Supporting Information. Files available from the ACS website may be downloaded for personal use only. Users are not otherwise permitted to reproduce, republish, redistribute, or sell any Supporting Information from the ACS website, either in whole or in part, in either machine-readable form or any other form without permission from the American Chemical Society. For permission to reproduce, republish and redistribute this material, requesters must process their own requests via the RightsLink permission system. Information about how to use the RightsLink permission system can be found at http://pubs.acs.org/page/copyright/permissions.html.

\section{Acknowledgment}

This work was funded by Marquette University. Calculations were performed on the high-performance computing cluster Père at Marquette University funded by NSF awards OCI-0923037 and CBET-0521602. The authors wish to thank Prof. Daniel S. Sem (Concordia University Wisconsin) for stimulating discussions regarding ${ }^{15} \mathrm{~N}$ NMR spectroscopy of RSNOs.

\section{References}

1 Williams, D. L. H. Acc. Chem. Res. 1999, 32, 869- 876

2 Broniowska, K. A.; Hogg, N. Antioxid. Redox Signaling 2012, 17, 969-980

3 Smith, B. C.; Marletta, M. A. Curr. Opin. Chem. Biol. 2012, 16, 498- 506

4 Koppenol, W. H. Inorg. Chem. 2012, 51, 5637- 5641

5 Filipovic, M. R.; Miljkovic, J. L.; Nauser, T.; Royzen, M.; Klos, K.; Shubina, T.; Koppenol, W. H.; Lippard, S. J.; Ivanović-Burmazović, I. J. Am. Chem. Soc. 2012, 134, 12016- 12027

6 The term S-nitrosylation is also used in the literature by analogy with other post-translational protein modifications, e.g., phosphorylation, glycosylation, etc., although in chemistry nitrosylation refers to coordination of nirtic oxide with transition metals.

7 Stamler, J. S.; Simon, D. I.; Osborne, J. A.; Mullins, M. E.; Jaraki, O.; Michel, T.; Singel, D. J.; Loscalzo, J. Proc. Natl. Acad. Sci. U.S.A. 1992, 89, 444- 448

8 Liu, L.; Hausladen, A.; Zeng, M.; Que, L.; Heitman, J.; Stamler, J. S. Nature 2001, 410, 490- 494

9 Hess, D. T.; Matsumoto, A.; Nudelman, R.; Stamler, J. S. Nat. Cell Biol. 2001, 3, E46- E49

10 Lane, P.; Hao, G.; Gross, S. S. Sci. STKE 2001, 2001, re1- re9

11 Hess, D. T.; Matsumoto, A.; Kim, S.-O.; Marshall, H. E.; Stamler, J. S. Nat. Rev. Mol. Cell Biol. 2005, 6, $150-166$

12 Derakhshan, B.; Hao, G.; Gross, S. S. Cardiovasc. Res. 2007, 75, 210- 219

13 Martínez-Ruiz, A.; Cadenas, S.; Lamas, S. Free Radical Biol. Med. 2011, 51, 17- 29

14 Astier, J.; Kulik, A.; Koen, E.; Besson-Bard, A.; Bourque, S.; Jeandroz, S.; Lamotte, O.; Wendehenne, D. Free Radical Biol. Med. 2012, 53, 1101- 1110

15 Seth, D.; Hausladen, A.; Wang, Y.-J.; Stamler, J. S. Science 2012, 336, 470-473

16 Mitchell, D. A.; Marletta, M. A. Nat. Chem. Biol. 2005, 1, 154- 158

17 Anand, P.; Stamler, J. S. J. Mol. Med. (Berlin) 2012, 90, 233- 244

18 Seth, D.; Stamler, J. S. Curr. Opin. Cell Biol. 2011, 15, 129-136

19 Doulias, P.-T.; Greene, J. L.; Greco, T. M.; Tenopoulou, M.; Seeholzer, S. H.; Dunbrack, R. L.; Ischiropoulos, H. Proc. Natl. Acad. Sci. U.S.A. 2010, 107, 16958-16963 
20 Zhang, Y.; Hogg, N. Free Radical Biol. Med. 2005, 38, 831- 838

21 Bosworth, C. A.; Toledo, J. C.; Zmijewski, J. W.; Li, Q.; Lancaster, J. R. Proc. Natl. Acad. Sci.

U.S.A. 2009, 106, 4671- 4676

22 Oae, S.; Kim, Y. H.; Fukushima, D.; Shinhama, K. J. Chem. Soc., Perkin Trans. 1 1978, 913- 917

23 Park, J. Biochem. Biophys. Res. Commun. 1988, 152, 916- 920

24 Wong, P. S.; Hyun, J.; Fukuto, J. M.; Shirota, F. N.; DeMaster, E. G.; Shoeman, D. W.; Nagasawa, H.

T. Biochemistry 1998, 37, 5362- 5371

25 Dalle-Donne, I.; Rossi, R.; Colombo, G.; Giustarini, D.; Milzani, A. Trends Biochem. Sci. 2009, 34, 85- 96

26 Flores-Santana, W.; Salmon, D. J.; Donzelli, S.; Switzer, C. H.; Basudhar, D.; Ridnour, L.; Cheng, R.; Glynn, S.

A.; Paolocci, N.; Fukuto, J. M.Antioxid. Redox Signaling 2011, 14, 1659- 1674

27 Tocchetti, C. G.; Stanley, B. A.; Murray, C. I.; Sivakumaran, V.; Donzelli, S.; Mancardi, D.; Pagliaro, P.; Gao, W.

D.; van Eyk, J.; Kass, D. A.Antioxid. Redox Signaling 2011, 14, 1687- 1698

28 Stamler, J. S. Cell 1994, 78, 931-936

29 Stamler, J. S.; Toone, E. J.; Lipton, S. A.; Sucher, N. J. Neuron 1997, 18, 691- 696

30 Greco, T. M.; Hodara, R.; Parastatidis, I.; Heijnen, H. F. G.; Dennehy, M. K.; Liebler, D. C.; Ischiropoulos, H. Proc. Natl. Acad. Sci. U.S.A. 2006, 103, 7420- 7245

31 Hao, G.; Derakhshan, B.; Shi, L.; Campagne, F.; Gross, S. S. Proc. Natl. Acad. Sci. U.S.A. 2006, 103, 1012-1017

32 Chen, Y.-J.; Ku, W.-C.; Lin, P.-Y.; Chou, H.-C.; Khoo, K.-H.; Chen, Y.-J. J. Proteome 2010, 9, 6417- 6439

33 Kohr, M. J.; Aponte, A. M.; Sun, J.; Wang, G.; Murphy, E.; Gucek, M.; Steenbergen, C. Am. J. Physiol., Heart

C 2011, 300, H1327-H1335

34 Pérez-Mato, I.; Castro, C.; Ruiz, F. A.; Corrales, F. J.; Mato, J. M. J. Biol. Chem. 1999, 274, 17075- 17079

35 Ascenzi, P.; Colasanti, M.; Persichini, T.; Muolo, M.; Polticelli, F.; Venturini, G.; Bordo, D.; Bolognesi, M. Biol. Chem. 2000, 381, 623-627

36 Marino, S. M.; Gladyshev, V. N. J. Mol. Biol. 2010, 395, 844- 859

37 Bartberger, M. D.; Mannion, J. D.; Powell, S. C.; Stamler, J. S.; Houk, K. N.; Toone, E. J. J. Am. Chem.

Soc. 2001, 123, 8868- 8869

38 Wang, P. G.; Xian, M.; Tang, X.; Wu, X.; Wen, Z.; Cai, T.; Janczuk, A. J. Chem. Rev. 2002, 102, 1091- 1134

39 Baciu, C.; Gauld, J. W. J. Phys. Chem. A 2003, 107, 9946- 9952

40 Timerghazin, Q. K.; Peslherbe, G. H.; English, A. M. Phys. Chem. Chem. Phys. 2008, 10, 1532- 1539

41 Arulsamy, N.; Bohle, D. S.; Butt, J. A.; Irvine, G. J.; Jordan, P. A.; Sagan, E. J. Am. Chem.

Soc. 1999, 121, 7115- 7123

42 Bartberger, M. D.; Houk, K. N.; Powell, S. C.; Mannion, J. D.; Lo, K. Y.; Stamler, J. S.; Toone, E. J. J. Am. Chem. Soc. 2000, 122, 5889- 5890

43 Toubin, C.; Yeung, D. Y.-H.; English, A. M.; Peslherbe, G. H. J. Am. Chem. Soc. 2002, 124, 14816- 14817

44 Baciu, C.; Cho, K.-B.; Gauld, J. W. J. Phys. Chem. B 2005, 109, 1334- 1336

45 Stubauer, G.; Giuffrè, A.; Sarti, P. J. Biol. Chem. 1999, 274, 28128- 28133

46 Perissinotti, L. L.; Estrin, D. A.; Leitus, G.; Doctorovich, F. J. Am. Chem. Soc. 2006, 128, 2512- 2513

47 Perissinotti, L. L.; Leitus, G.; Shimon, L.; Estrin, D.; Doctorovich, F. Inorg. Chem. 2008, 47, 4723- 4733

48 Timerghazin, Q. K.; Peslherbe, G. H.; English, A. M. Org. Lett. 2007, 9, 3049-3052

49 Moran, E. E.; Timerghazin, Q. K.; Kwong, E.; English, A. M. J. Phys. Chem. B 2011, 115, 3112- 3126

50 Timerghazin, Q. K.; English, A. M.; Peslherbe, G. H. Chem. Phys. Lett. 2008, 454, 24- 29

51 Roy, B.; du Moulinet d'Hardemare, A.; Fontecave, M. J. Org. Chem. 1994, 59, 7019- 7026

52 Bharatam, P. V.; Senthilkumar, P. Tetrahedron 2004, 60, 4801- 4805

53 Weinhold, F.; Landis, C. R. Valency and Bonding: A Natural Bond Orbital Donor-Acceptor

Perspective; Cambridge University Press: New York, 2003.

54 Glendening, E.; Weinhold, F. J. Comput. Chem. 1998, 19, 593- 609

55 Glendening, E.; Weinhold, F. J. Comput. Chem. 1998, 19, 610- 627

56 Glendening, E.; Badenhoop, J.; Weinhold, F. J. Comput. Chem. 1998, 19, 628-646

57 Frey, D.; Braun, O.; Briand, C.; Vašák, M.; Grütter, M. G. Structure 2006, 14, 901- 911 
58 Schreiter, E. R.; Rodríguez, M. M.; Weichsel, A.; Montfort, W. R.; Bonaventura, J. J. Biol.

Chem. 2007, 282, 19773- 19780

59 Weichsel, A.; Brailey, J. L.; Montfort, W. R. Biochemistry 2007, 46, 1219- 1227

60 Chowdhury, R.; Flashman, E.; Mecinović, J.; Kramer, H. B.; Kessler, B. M.; Frapart, Y. M.; Boucher, J.-L.; Clifton, I. J.; McDonough, M. A.; Schofield, C. J. J. Mol. Biol. 2011, 410, 268- 279

61 Skaff, D. A.; Ramyar, K. X.; McWhorter, W. J.; Barta, M. L.; Geisbrecht, B. V.; Miziorko, H.

M. Biochemistry 2012, 51, 4713-4722

62 Frisch, M. J.Gaussian 09, Revision A.01; Gaussian Inc.: Wallingford, CT, 2009.

63 Perdew, J. P.; Burke, K.; Ernzerhof, M. Phys. Rev. Lett. 1996, 77, 3865- 3868

64 Adamo, C.; Barone, V. J. Chem. Phys. 1999, 110, 6158-6170

65 Weigend, F.; Ahlrichs, R. Phys. Chem. Chem. Phys. 2005, 7, 3297- 3305

66 Rappoport, D.; Furche, F. J. Chem. Phys. 2010, 133, 134105

67 Schuchardt, K. L.; Didier, B. T.; Elsethagen, T.; Sun, L.; Gurumoorthi, V.; Chase, J.; Li, J.; Windus, T. L. J. Chem. Inf. Model. 2007, 47, 1045- 1052

68 Feller, D. J. Comput. Chem. 1996, 17, 1571- 1586

69 Wang, N. X.; Wilson, A. K. J. Phys. Chem. A 2005, 109, 7187- 7196

70 Cances, M. T.; Mennucci, V.; Tomasi, J. J. Chem. Phys. 1997, 107, 3032- 3041

71 Duan, Y.; Wu, C.; Chowdhury, S.; Lee, M. C.; Xiong, G.; Zhang, W.; Yang, R.; Cieplak, P.; Luo, R.; Lee, T.J. Comput. Chem. 2003, 24, 1999- 2012

72 Henkelman, G.; Jónsson, H. J. Chem. Phys. 2000, 113, 9978-9985

73 Kästner, J.; Carr, J. M.; Keal, T. W.; Thiel, W.; Wander, A.; Sherwood, P. J. Phys. Chem.

A 2009, 113, 11856-11865

74 ChemShell, a Computational Chemistry Shell; www.chemshell.org.

75 Dapprich, S. J. Mol. Struct.: THEOCHEM 1999, 461-462, 1- 21

76 Vreven, T.; Mennucci, B.; da Silva, C. O.; Morokuma, K.; Tomasi, J. J. Chem. Phys. 2001, 115, 62- 72

77 Cornell, W. D.; Cieplak, P.; Bayly, C. I.; Gould, I. R.; Merz, K. M.; Ferguson, D. M.; Spellmeyer, D. C.; Fox, T.J. Am. Chem. Soc. 1995, 117, 5179- 5197

78 Wang, J.; Wang, W.; Kollman, P. A.; Case, D. A. J. Mol. Graphics Modell. 2006, 25, 247- 260

79 Wang, J.; Wolf, R. M.; Caldwell, J. W.; Kollman, P. A.; Case, D. A. J. Comput. Chem. 2004, 25, 1157- 1174

80 Dupradeau, F.-Y.; Pigache, A.; Zaffran, T.; Savineau, C.; Lelong, R.; Grivel, N.; Lelong, D.; Rosanski, W.; Cieplak, P. Phys. Chem. Chem. Phys. 2010, 12, 7821- 7839

81 Hinsen, K. J. Comput. Chem. 2000, 21, 79- 85

82 Glendening, E. D.; Badenshoop, J.; Reed, A. E.; Carpenter, J. E.; Bohmann, J. A.; Morales, C. M.; Weinhold, F. NBO 5.9; Theoretical Chemistry Institute, University of Wisconsin: Madison, WI, 2009.

83 Wolinski, K.; Hinton, J. F.; Pulay, P. J. Am. Chem. Soc. 1990, 112, 8251- 8260

84 Gauss, J. Chem. Phys. Lett. 1992, 191, 614-620

85 Jensen, F. J. Chem. Theory 2008, 4, 719- 727

86 Although the results for the lysine model complexes presented in this work qualitatively agree with ref 48 , they differ qualitatively because of solvation effects inclusion, different basis set, and multireference NRT procedure with predefined reference structures used here.

87 Subsequent saddle point optimization starting from the maximum energy point failed to locate a transition structure.

88 Politzer, P.; Murray, J. S.; Clark, T. Phys. Chem. Chem. Phys. 2010, 12, 7748- 7757

89 Abrams, A. J.; Farooq, A.; Wang, G. Biochemistry 2011, 50, 3405- 3407

90 Molecular dynamics (MD) simulations of $S$-nitrosated thioredoxin can clarify the importance of this and other interactions predicted with LEM analyses, although they require a reliable force-field description of the -SNO interactions with charged residues. Development of such force field is underway: Ivanov, M.;

Talipov, M. R.; Timerghazin, Q. K. Manuscript in preparation.

91 Bonnett, R.; Holleyhead, R.; Johnson, B. L.; Randall, E. W. J. Chem. Soc. Perkin Trans. 1 1975, 22, 2261- 2241 
92 Simon, D. I.; Mullins, M. E.; Jia, L.; Gaston, B.; Singel, D. J.; Stamler, J. S. Proc. Natl. Acad. Sci. U.S.A. 1996, 93, 4736- 4741

93 Wang, K.; Hou, Y.; Zhang, W.; Ksebati, M. B.; Xian, M.; Cheng, J.-P.; Wang, P. G. Bioorg. Med. Chem. Lett. 1999, 9, 2897- 2902

94 Sonnenschein, K.; de Groot, H.; Kirsch, M. J. Biol. Chem. 2004, 279, 45433- 45440

95 Tao, L.; English, A. M. Biochemistry 2003, 42, 3326- 3334

96 Kojetin, D. J.; Venters, R. A.; Kordys, D. R.; Thompson, R. J.; Kumar, R.; Cavanagh, J. Nat. Struct. Mol. Biol. 2006, 13, 641-647 